\title{
A Highly Abundant Transcript in Adult Murine Cerebellar Granule Cells Contains Repetitive Sequences Homologous to L1
}

\author{
H. Schaal, D. Goldowitz, ${ }^{1}$ U. A. O. Heinlein, A. Unterbeck, C. Ruppert, \\ T. Papenbrock, B. Müller-Hill, W. Vielmetter, and W. Wille
}

Institute of Genetics, University of Cologne, D-5000 Cologne 41, Federal Republic of Germany, and 'Department of Anatomy, Thomas Jefferson University, Philadelphia, Pennsylvania 19107

\begin{abstract}
Cloned cDNA from adult mouse cerebellum composed of subsequences homologous to the L1Md consensus sequence (long interspersed repetitive element "LINE" family of the mouse) hybridizes specifically with large nuclear poly $(A)+$ RNAs that are highly concentrated in the murine and rat cerebellum. These homogeneous L1-related transcripts were localized in the mouse CNS by in situ hybridization with ${ }^{3} \mathrm{H}$ - and biotin-labeled DNA probes. They were found to hybridize to cerebellar granule cells specifically.
\end{abstract}

Interspersed repetitive elements are ubiquitous characteristics of eukaryotic DNA (Rogers, 1985). In rodents and primates, they can be assigned to relatively few, molecularly well characterized families (Krayev et al., 1980, 1982; Singer, 1982; Singer et al., 1983; Voliva et al., 1984; Singer and Skowronski, 1985). In addition to the short interspersed repetitive elements (SINEs), a family of long interspersed repetitive elements (LINEs) has been described (Singer, 1982; Kole et al., 1983; Voliva et al., 1984; Singer and Skowronski, 1985), which exhibits significant homologies between rodents and primates (Singer et al., 1983).

The approximately 7-kilobase (kb)-long murine LINE analog L1Md (LINE-1 from Mus domesticus; Voliva et al., 1984; Singer and Skowronski, 1985) is composed of several independently discovered short repetitive fragments: R, Bam5, E24 [the term "E27" will be used here because of its real length of 270 base pairs (bp)], and MIF (Fanning, 1982, 1983; Brown and Piechaczyk, 1983; Gebhard and Zachau, 1983; Bennett and Hastie, 1984).

LINEs seem to originate from protein-coding single-copy genes that created pseudogenes by gene duplication. A high copy number of LINEs was then introduced into various sites of the chromosomal DNA by a retroposition mechanism via RNA intermediates and their reverse transcripts (Baltimore, 1985; Rogers, 1985; Soares et al., 1985; Deininger and Daniels, 1986). A num-

\footnotetext{
Received June 18, 1986; revised Dec. 17, 1986; accepted Dec. 23, 1986.

This work was supported by the Deutsche Forschungsgemeinschaft, Schwerpunktprogramm "Biochemie des Nervensystems," through grants Wi563/3-2 and Wi563/3-3 to W.W. and through fellowships from the DAAD to D.G. and W.W. A.U. was supported by the Bundesministerium für Wissenschaft und Forschung through Grant BCT $0365 / 2$ to B.M.-H. We wish to thank R. Lange-Sablitzky, G. Vopper, and $\mathrm{H}$. Thielsch for excellent technical assistance, students M. Detlefs and R. Höfgen for experimental help, Dr. K. Olek for SV40 linker and tailed vector, Dr. $\mathrm{H}$. Esche for his advice in preparing reticulocyte lysates, and Dr. P. Eckes for fruitful discussions.

Correspondence should be addressed to Dr. Wolfgang E. Wille, Institut für Genetik der Universität zu Köln, Weyertal 121, D-5000 Köln 41, F.R.G. Copyright (c) 1987 Society for Neuroscience $0270-6474 / 87 / 072041-08 \$ 02.00 / 0$
}

ber of questions cannot yet be answered: (1) Do repetitive element familics scrve regulatory functions (Davidson and Britten, 1979; Sutcliffe and Milner, 1984), or have they evolved as a result of random duplication and deletion events (Loomis and Gilpin, 1986)? (2) Have some members of randomly generated repeat families gained a functional role in regulatory mechanisms later in evolution?

In this paper we report the cell-specific accumulation of LINErelated transcripts in the mature murine and rat cerebellum.

\section{Materials and Methods}

Chemicals. Guanidine thiocyanate was obtained from Fluka (Buchs, Switzerland), $N$-lauroylsarcosine from Serva (Heidelberg), oligo(dT)cellulose type III from Collaborative Research Inc. (Lexington, MA), hemin from Eastman-Kodak (Rochester, NY), bio-16-dUTP and streptavidin-alkaline phosphatase from Enzo Biochem (New York, NY), and AMV reverse transcriptase and RNase $\mathrm{H}$ from Stehelin (Basel, Switzerland). HAHY nitrocellulose paper was purchased from Millipore (Ncu-Isenburg) and GeneScreenPlus ${ }^{\oplus}$ nylon membranc from New England Nuclear (Boston). All other chemicals were of analytical grade and procured from Sigma or Merck (Darmstadt). All enzymes were obtained from Biolabs (Schwalbach), Boehringer (Mannheim), BRL (Eggenstein), Pharmacia (Freiburg), or Renner (Dannstadt). All radioactive compounds were purchased from Amersham-Buchler (Braunschweig).

Isolation of RNA. Mouse tissues were obtained from $\mathrm{C} 57 \mathrm{BL} / 6 \mathrm{~J}$ mice raised in our breeding colony, dissected immediately after decapitation, and either immediately used or stored in liquid nitrogen. Experiments with fresh and stored tissues, respectively, revealed identical results. Control experiments were carried out with different mouse strains from the animal facilities at Jefferson University, Philadelphia. Sprague-Dawley rats were obtained from the Institute of Human Genetics (Bonn, FRG). Neonatal cerebella were dissected with the aid of a microscope in order to avoid contamination with noncerebellar tissue. RNA was purified according to Kaplan et al. (1979), with minor modifications. Tissues were homogenized (Polytron, Kinematica, Kriens, Switzerland) in at least $10 \mathrm{vol}$ of $5.0 \mathrm{M}$ guanidine thiocyanate $/ 50 \mathrm{~mm}$ TrisHCl, pH 7.6/10 mM EDTA/0.1 м 2-mercaptoethanol/0.1\% Antifoam A. The homogenization buffer was filtered through Whatman 3MM paper prior to use. For preparation of nuclear RNA, tissues were homogenized in 5 vol of ice-cold nucleus buffer containing $50 \mathrm{~mm}$ TrisHCl, $\mathrm{pH} 7.5 / 25$ $\mathrm{mm} \mathrm{NaCl} / 250 \mathrm{~mm}$ sucrose/ $0.5 \% \mathrm{NP}-40 / 10 \mathrm{~mm}$ vanadylribonucleoside complexes. The homogenate was centrifuged for $10 \mathrm{~min}$ at $1000 \times \mathrm{g}$. The resulting pellet was washed twice with the same buffer and resuspended in homogenization buffer.

The homogenate was centrifuged for $10 \mathrm{~min}$ at $15^{\circ} \mathrm{C}$ in a Sorvall $\mathrm{HB}-4$ rotor $(8000 \mathrm{rpm})$. The supernatant was adjusted to $4 \%$ (wt/vol) $N$-lauroylsarcosine and $0.15 \mathrm{~g} / \mathrm{ml} \mathrm{CsCl}$. The solution was layered on a $2 \mathrm{ml}$ $\mathrm{CsCl}$ cushion $(5.7 \mathrm{M} \mathrm{CsCl} / 0.1 \mathrm{~m}$ EDTA, $\mathrm{pH} 7.0)$ and centrifuged with $36,000 \mathrm{rpm}$ for $20 \mathrm{hr}$ at $20^{\circ} \mathrm{C}$ in a Beckman SW41 rotor. After careful aspiration of the supernatant, the RNA pellet was suspended in diethylpyrocarbonate-treated water at $65^{\circ} \mathrm{C}$ and extracted twice with phenol/ chloroform/isoamylol (25:24:1). The RNA was precipitated by addition of $6.0 \mathrm{M}$ ammonium acetate $(4 \%, \mathrm{vol} / \mathrm{vol})$ and 2 vol of ethanol, resuspended in water, and stored in $70 \%$ ethanol. 
Isolation of poly $(A)+R N A$. Poly(A)+ RNA was purified by oligo(dT)cellulose chromatography (Aviv and Leder, 1972), as described by Efstratiadis and Kafatos (1976), except that $\mathrm{NaCl}$ was used instead of $\mathrm{KCl}$ in the binding buffer. The quality of poly $(\mathrm{A})^{+} \mathrm{RNA}$ preparations was determined by in vitro translation. Poly $(\mathrm{A})^{+} \mathrm{RNA}$ was translated in micrococcus nuclease-treated reticulocyte lysate (Pelham and Jackson, 1976), which was prepared in cooperation with Dr. H. Esche (Essen). Lysates obtained from individual rabbits were separately tested for optimal potassium and magnesium requirements prior to use. In most cases, addition of hemin was omitted because different amounts of hemin gave inconsistent results. All poly $(\mathrm{A})^{+}$RNAs used directed the synthesis of proteins ranging from low molecular weights up to $>100$ $\mathrm{kDa}$, as determined by 2 -dimensional polyacrylamide gel analysis.

cDNA synthesis and cloning. Plasmid-primed cDNA synthesis was carried out by the method of Okayama and Berg (1983). Tailed vector and SV40 linker fragment were generous gifts of Dr. K. Olek (Bonn). Poly $(\mathrm{A})^{+}$RNA preparations from adult mouse cerebellum served as the source for the construction of the cDNA library. After transformation and plating of small aliquots, the number of recombinant clones in the cDNA library was calculated to be 255,000 . The size distribution showed an average insert size of $>500 \mathrm{bp}$. Approximately $15 \%$ of the clones were linker-free recombinants. This may have been due to the known ability of certain type II-restriction enzymes to cut RNA:DNA hybrids (Molloy and Symons, 1980).

Screening of cDNA libraries for brain-specific inserts. Recombinant vector DNA was transformed into competent $E$. coli RR $1 \Delta \mathrm{M} 15$ cells (Hanahan, 1983) with predetermined transformation efficiencies of at least $2 \times 10^{7}$ clones $/ \mu$ g supercoiled pBR322 DNA. Plasmid preparations of ampicillin-resistant colonies (Holmes and Quigley, 1981) were routinely checked for inserts by digestion with XhoI. Single plasmid-harboring clones were transferred to Falcon 96 well microtiter plates containing medium with glycerol (Taub and Thompson, 1982). Glycerol stocks were checked for tissue-specific inserts by transfer of the DNA to Whatman 541 paper (Taub and Thompson, 1982) and hybridization with ${ }^{32}$ P-labeled cDNAs from various tissues (see Results).

Clones of interest were grown from the microtiter stocks, and their plasmids were isolated (Holmes and Quigley, 1981) and inserts released with BamHI and BamHI/ClaI, respectively. After separation by agarose gel electrophoresis, DNA was transferred to nitrocellulose or nylon filters (Southern, 1975) and hybridized again with ${ }^{32} \mathrm{P}-\mathrm{cDNAs}$ from different tissues. Verified brain-specific inserts were subcloned into pSP6-4 and pSP6-5 vectors (Melton et al., 1984) for further analysis.

DNA sequencing was carried out after subcloning into $\mathrm{M} 13 \mathrm{mp} 8$ and M13mp9 phages (Sanger et al., 1977; Messing and Vieira, 1982; Biggin et al., 1983).

Southern and Northern blot hybridizations. Nitrocellulose or nylon filters carrying immobilized DNA probes were prehybridized for 4-6 $\mathrm{hr}$ in $50 \%$ formamide $/ 5 \times \mathrm{SSC} / 5 \times$ Denhardt's solution (Denhardt, 1966)/ $100 \mu \mathrm{g} / \mathrm{ml}$ denatured salmon sperm DNA $100 \mu \mathrm{g} / \mathrm{ml}$ denatured $E$. coli RR $1 \Delta$ M 15 DNA $100 \mu \mathrm{g} / \mathrm{ml}$ poly(U) at $42^{\circ} \mathrm{C}$. Nick-translated DNA probes (Rigby et al., 1977) were boiled for $5 \mathrm{~min}$ in the same solution prior to addition to the prehybridization fluid. Hybridizations were carried out for $20-30 \mathrm{hr}$ at $42^{\circ} \mathrm{C}$. Filters were washed for $2 \times 15 \mathrm{~min}$ at room temperature with $2 \times \mathrm{SSC} / 0.1 \% \mathrm{SDS}$ followed by $3 \times 15 \mathrm{~min}$ rinses with $0.1 \times \mathrm{SSC} / 0.1 \% \mathrm{SDS}$ at $65^{\circ} \mathrm{C}$.

Northern blots were hybridized in the same buffer as described, which also contained $50 \mathrm{~mm}$ sodium phosphate buffer, $\mathrm{pH} 7.0$, and $100 \mu \mathrm{g} /$ $\mathrm{ml}$ poly $(\mathrm{C})$. The final $0.1 \times \mathrm{SSC}$ washes were done at $42^{\circ} \mathrm{C}$.

For control experiments RNAs were digested with $10 \mu \mathrm{g}$ RNase for $40 \mathrm{~min}$ at $37^{\circ} \mathrm{C}$

Isolation of Bam 5 and E27 subclones. Genomic mouse DNA (10 $\mu \mathrm{g})$ was digested with EcoRI and PstI and separated on an agarose gel. DNA fragments $1-1.5 \mathrm{~kb}$ long were isolated by insertion of a NA-45 DEAE ion-exchange membrane (Lizardi et al., 1984) and cloned into EcoRI/ PstI-digested M13mp8 RF DNA (Messing and Vieira, 1982). Phage RF DNA carrying genomic repetitive mouse sequences was prepared (Holmes and Quigley, 1981), digested with EcoRI and Pstl, run on agarose gels, and transferred to nitrocellulose papers (Southern, 1975). These were probed with nick-translated CebA1 17 DNA. Two out of 6 positive M13 clones were subjected to sequence analysis (Sanger et al., 1977). Clone m8-RS13 contained both the FcoRI/BamHI E27 fragment $(0.27 \mathrm{~kb})$ and the BamHI/BamHI Bam5 fragment $(0.55 \mathrm{~kb})$ with intact EcoRI and BamHI sites. Both fragments were subcloned into pSP6-4 vector.

Strand specificity. For determination of strand specificity Northern blot hybridization was carried out using primer-labeled M13 template containing either the single-stranded anti-sense sequence of the R-subfragment (m8-RS5) or the sense sequence of the E27, Bam5, and portions of the R-subfragment (m8-RS13).

Computer analysis. Computer analyscs wcre carricd out on the VAX/ VMS system with the wORDSEARCH and BESTFIT programs, respectively (Wilbur and Lipman, 1983; Devereux et al., 1984).

In situ hybridization. Mice were perfused with saline followed by a mixture of $75 \%$ ethanol and $25 \%$ glacial acetic acid. Brains were removed, dehydrated in alcohol, cleared in xylene, and embedded in paraffin. Sections $4 \mu \mathrm{m}$ thick were cut and mounted on poly(-L-lysine)coated slides. Deparaffinized sections of tissue were prehybridized at $40^{\circ} \mathrm{C}$ for $1 \mathrm{hr}$ with hybridization solution $[2.5 \times \mathrm{SSC}, 30 \%$ formamide, $1 \times$ Denhardt's, $250 \mu \mathrm{g} / \mathrm{ml}$ salmon sperm DNA, and $100 \mu \mathrm{g} / \mathrm{ml}$ poly $(-\mathrm{U})]$ without probe but containing $5 \mu \mathrm{g} / \mathrm{ml} \mathrm{M} 13$ DNA (BRL). Tissue sections were rinsed in ascending alcohol solutions, air-dried, and hybridized at $40^{\circ} \mathrm{C}$ overnight with $50-100 \mathrm{ng}$ cDNA probe in 10-20 $\mu$ l hybridization solution. Probes were nick-translated with either biotinylated dUTP (Enzo Biochem) or ${ }^{3} \mathrm{H}-\mathrm{dCTP}$ and -dTTP. Probes were typically labeled to an equivalent specific activity of about $1 \times 10^{7} \mathrm{cpm} / \mu \mathrm{g} \mathrm{DNA}$. Labeled probes were separated from free nucleotides by passing them over a G-50 column. After hybridization, tissue sections were rinsed twice in $2 \times \mathrm{SSC}$ and $1 \times \mathrm{SSC}$ at $40^{\circ} \mathrm{C}$ and $0.1 \times \mathrm{SSC}$ at room temperature. Slides were finally rinsed in $\mathrm{H}_{2} \mathrm{O}$ or $0.1 \mathrm{M}$ phosphate buffer ( $\mathrm{pH} 7.2$ ) prior to detection. Tissue exposed to biotinylated CebAll 17 was reacted with Enzo Detek I-alk signal-generating system to yield a blue reaction product at sites of hybridization. Tissue that was hybridized with $a^{3} \mathrm{H}$-probe was coated with Kodak NTB-2 emulsion, exposed for 2 weeks at $4^{\circ} \mathrm{C}$, and developed with Kodak D-19 at $16^{\circ} \mathrm{C}$ for $4 \mathrm{~min}$. Clusters of silver grains that were 2 or more times higher than hackground grain density were presumed to be sites of specific CebAl17 hybridization.

\section{Results}

In the course of a 3-step differential screening procedure for sequences specifically expressed in the mouse cerebellum, 2 clones from an adult cerebellar cDNA library (see Materials and Methods) attracted particular notice. Insert-DNA of both clones, CebA117 and CebAB2, revealed strong hybridization signals with single-stranded cDNA from cerebellum but not from total brain minus cerebellum, liver, or kidney. CebA117 was homologous in its entirety to parts of the repetitive $\mathrm{Ll}$ consensus sequence (Voliva et al., 1984) (Fig. 1), although in a rather uncommon sequence order. Thus, CebA1 17 contained only part of the $R$ and the E27 sequence, and the latter was inverted relative to $R$ in the normal $L 1$ consensus sequence. A possible DNA inversion event of the transcribed region may be responsible for the odd orientation. The second cDNA clone with an identical hybridization behavior (see below), CebAB2, was an L1 transcript in "normal"' sequence order containing the Bam5 and the $\mathrm{R}$ (but not the E27) fraction of the L1 consensus sequence. The homology between CebA1 17 and CebAB2 was $95 \%$ (not shown) when comparing equivalent parts of the 2 clones.

Both of these L1-related cDNA clones have been identified on the basis of the strong hybridization signal with cDNA and poly(A) ${ }^{+}$RNA populations derived exclusively from adult cerebellum. Figure 2 shows a Northern blot analysis of poly $(\mathrm{A})^{+}$RNAs from neonatal and adult cerebellum and total brain minus cerebellum $\left(\mathrm{TB}^{-}\right)$, respectively, hybridized with CebA117. Only the adult cerebellar poly $(\mathrm{A})^{+}$RNA contained a large (7-9 kb), abundant transcript recognized by either CebA117 (lane $e$ ), CebAB2, or subcloned E27, Bam5, and $\mathrm{R}$ sequences (identical blots to those in Fig. 2; not shown). Neither increasing amounts of applied poly $(\mathrm{A})^{+} \mathrm{RNA}$ derived from the control tissues nor elongated exposure times revealed a L1-specific hybridization signal (not shown).

On the other hand, highly repetitive, interspersed sequence families other than L1 (B1, B2) did not produce the high-mo- 


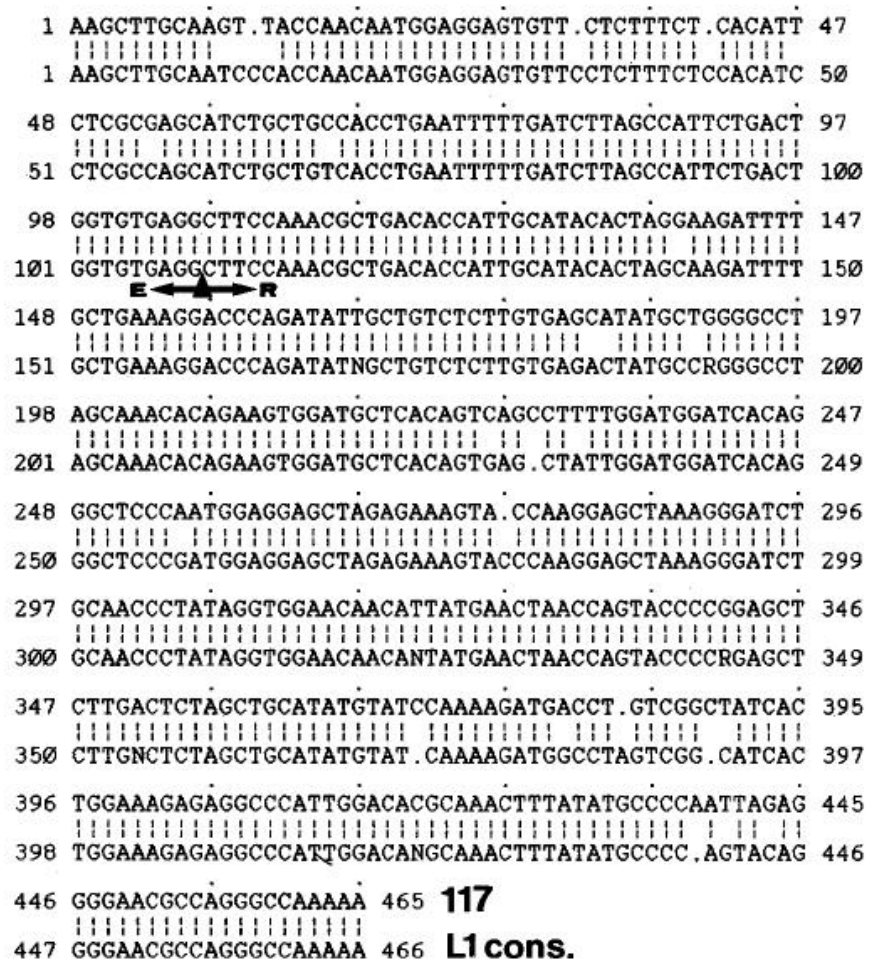

Figure 1. Computer analysis of homology between CebA117 and L1 consensus sequence (L1cons). Top line represents CebA117; bottom line, a homologous sequence assembled from L1cons (Voliva et al., 1984): left of triangle $(E)$ derives from reversed E27 (i.e., nucleotides 1052944 of L1 cons); right of the triangle $(R)$ from the R-part of L1 (nucleotides 1643-2000 of Llcons). The CebA117 sequence has been determined from both strands.

lecular-weight RNA signal in either poly(A)+ mRNA population (not shown).

Northern blots of total RNAs obtained from different murine and rat tissues revealed weak signals (intensity $<1 \%$ as compared with cerebellar RNA) in a variety of preparations (Fig. 3). In both, mouse and rat, only cerebellar RNA showed strong hybridization with the L1 subsequence E27. Thus, small amounts of nonpolyadenylated L1 transcripts seem to exist in various tissues; only the cerebellar granule cells, on the other hand, contain large amounts of both the poly(A) ${ }^{+}$and the poly(A)forms of this transcript. Hybridization of the Northern blots with other L1 subclones gave identical results (not shown). While in RNAs from total brain minus cerebellum, thymus, muscle, liver, and spleen the L1-related transcripts were of the same size as the cerebellar transcript, the identified RNA species in lung RNA seemed to be slightly smaller (Fig. 3, lane $G$ ). An entirely different hybridization pattern containing at least 11 bands was found in Northern blots of total RNA derived from heart muscle (Fig. 3, lane $H$; Fig. 4, lane $h$ ).

Northern blot hybridizations of adult cerebellar poly(A)+RNA using single-stranded $\mathrm{L} 1$ probes of both orientations (see Materials and Methods) revealed the described signal only with the anti-sense orientation (not shown).

Treatment of total RNA (Fig. 4) and poly(A) ${ }^{+}$mRNA (not shown), respectively, with ribonuclease (RNase), on the other hand, abolished the strong cerebellar hybridization signal. Also, most of the faint bands visible on Northern blots of RNA from total brain minus cerebellum, heart, and spleen disappeared

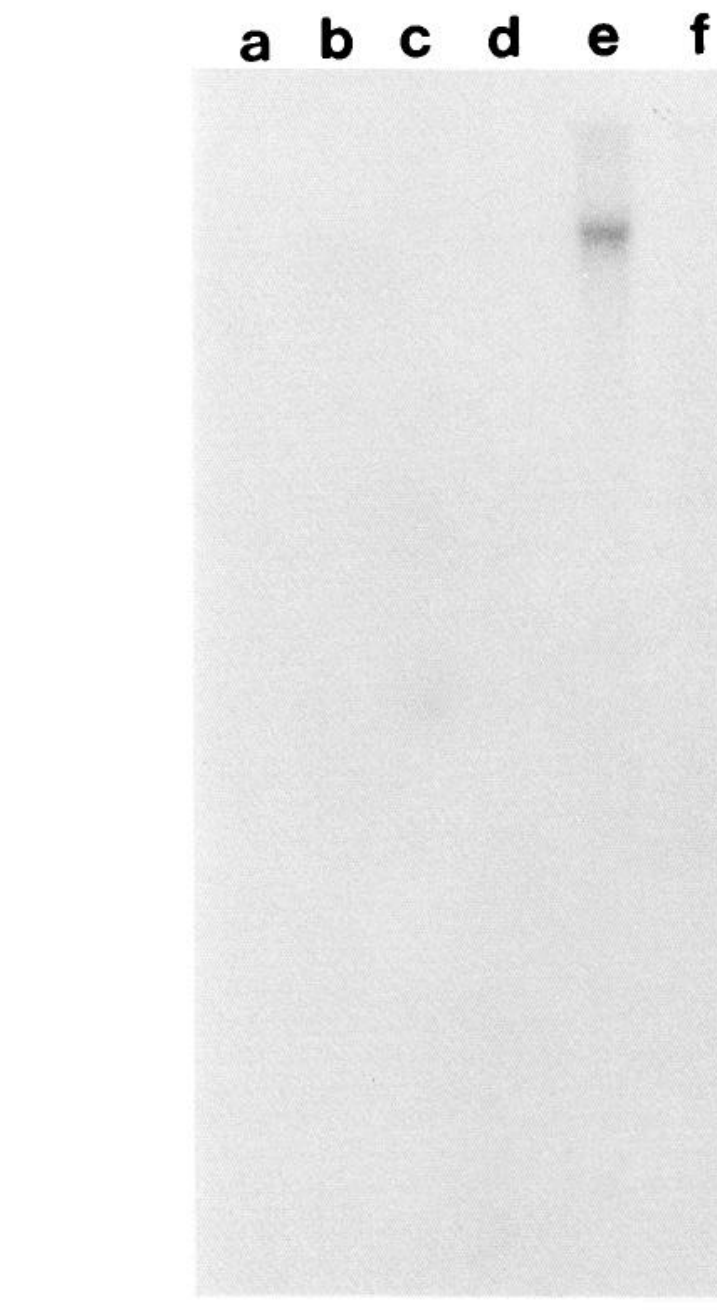

Figure 2. Northern blot analysis of poly $(\mathrm{A})^{+}$RNAs from different murine tissues using CebA117 as a probe. Poly(A) ${ }^{+}$RNAs, $2 \mu \mathrm{g}$, from different tissues and developmental stages were separated on formaldehyde/MOPS agarose gels. Lanes: $a$, adult kidney [poly(A) ${ }^{-}$]; $b$, adult kidney; $c$, neonatal total brain minus cerebellum; $d$, adult total brain minus cerebellum; $e$, adult cerebellum; $f$, neonatal cerebellum. Exposure time, $7 \mathrm{hr}$; after longer exposure times, the autoradiographs exhibited a background "smear" only in lanes $c, e$, and $f$. A signal of the same size as in $e$ was not detected in either lanes $c$ or $f$, even after long exposure times.

after digestion with RNase. Some of the bands from heart muscle were still detectable after intense RNase treatment (Fig. 4, arrows), while additional DNase treatment abolished the signal entirely (not shown).

Nuclear localization of the cerebellar L1-containing transcript was demonstrated by Northern blot analysis of cytoplasmic poly(A)+RNA, cerebellar nuclear RNA, and nuclear RNA of total brain probed with a mixture of nick-translated m8-RS5 and -RS13, containing the E27, Bam5, and R sequences (Fig. 5 , lanes $1-3)$.

CebA117, labeled with either tritium or biotin, was hybridized to sections of various tissues to determine the cellular localization of the transcript. Two patterns of hybridization resulted: (1) Only the cerebellar granule cells in brain exhibited hybridization (Fig. 6,a,c,e). The dark reaction product that fills the internal granular layer appears within (Fig. 6,a,c) or over (Fig. 6e) the entire perikaryon of the granule cell, including the 


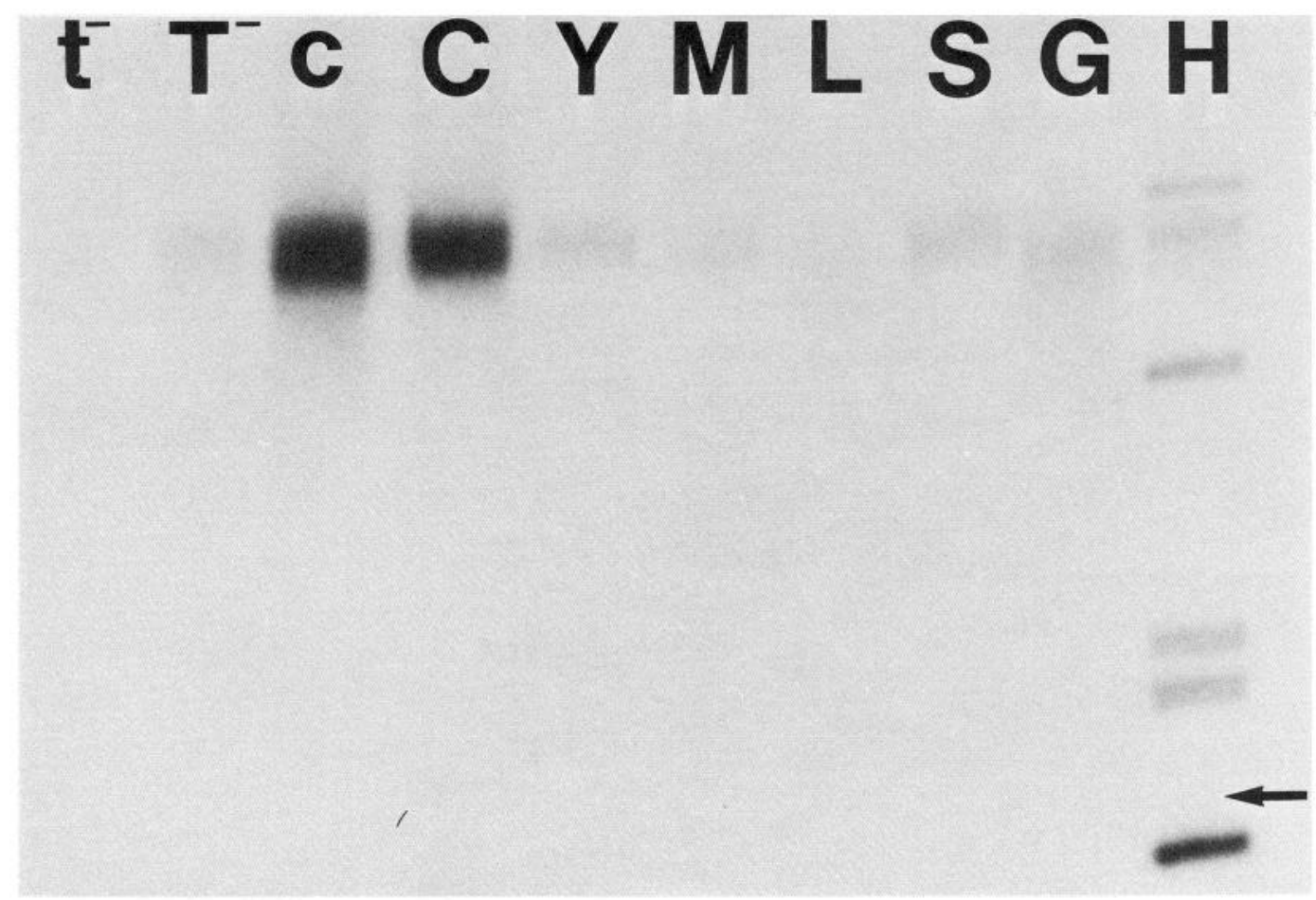

Figure 3. Northern blot analysis of total adult RNAs of different murine (upper-case letters) and rat (lower-case letters) tissues using the genomic E27 subclone as a probe. Total RNAs were separated by citrate/urea 1.5\% agarose gel electrophoresis (Lehrach et al., 1977), and the blots were hybridized against the genomic E27 subclone (see Materials and Methods) of the L1 sequence (Voliva et al., 1984). The arrow indicates the 28SRNA as determined by following hybridization with pMR100 (generous gift from I. Grummt), a clone containing the $6.6 \mathrm{~kb}$ EcoRI-fragment of ribosomal mouse DNA including the 28S-RNA sequence and the spacer. This control blot also confirmed that approximately equal amounts of RNA have been applied to each lane (not shown). $T^{-}\left(t^{-}\right)$, total brain minus cerebellum; $C(c)$, cerebellum; $Y$, thymus; $M$, striated muscle; $L$, liver; $S$, spleen; $G$, lung; $H$, heart.

nucleus, which is the predominant feature of the cell. Other cell types in brain such as the granule cells of the fascia dentata had no demonstrable hybridization signal (Fig. 6,b,d). (2) All nuclei in brain and other tissues (thymus, liver, kidney) demonstrated a hybridization signal.

It was not entirely predictable which of these outcomes would be achieved in a given experiment. However, after experimenting with numerous hybridization conditions (temperature, time, acid rinse, protein digestion, and heat pretreatment), we determined that experimental conditions that might allow the probe easier access to DNA (such as heating, acid rinse, etc.) yielded the result 2 , while milder hybridization conditions yielded the granule cell-specific hybridization signal (result 1). Additionally, RNase pretreatment $\left(100 \mu \mathrm{g} / \mathrm{ml}, 37^{\circ} \mathrm{C}, 1 \mathrm{hr}\right)$ abolished the granule cell-specific signal and resulted in nuclear hybridization to all cells in the brain.

\section{Discussion}

Both "Cb-positive" cDNA clones, CebA117 and CebAB2, apparently bind to the same large transcript in adult cerebellar poly $(\mathrm{A})^{+} \mathrm{RNA}$, although they seem to be reverse-transcribed from different RNA species. While CebAB2 consists of segments of the L1Md family in "normal" order (Voliva et al., 1984), CebA117 is composed of L1 fragments in inverted orientation (Fig. 1).

A similar combination of the E27 and R subsequences in opposite orientation (lacking the Bam5-sequence) has been found, for example, in the murine kallikrein gene, nucleotides 6349-
6767 (Mason et al., 1983). However, for the identification of the granule cell-specific L1Md transcript it is actually irrelevant whether the inverted composition of one of the original clones (CebA117) leading to its detection is real or a cloning artifact. In general, not only the $5^{\prime}$-truncation (Cooper et al., 1984; Voliva et al., 1984; Singer and Skowronski, 1985) but also rearrangements of the LINE sequences (DiGiovanni et al., 1983; Gebhard and Zachau, 1983; Lerman et al., 1983; Potter, 1984; Soares et al., 1985) seem to be common. For the time being, we cannot deduce from our data whether the L1-related cerebellar RNA is a homogeneously organized population of "normal" L1 transcripts or a mixed population of a variety of truncated and/or rearranged RNAs carrying L1Md-sequence elements. The relatively distinct size of these transcripts and the fact that they contain three L1-subsequences-R, Bam5, and E27 (but not the SINEs B1 or B2)-hint at the former alternative.

The applied procedure of differential screening for Cb-positive sequences (see above and Materials and Methods) yielded 11 clones $(42 \%)$ containing repetitive sequences as determined by hybridization with nick-translated genomic mouse DNA (not shown). Among these clones there is at least one (CebA847) containing the repetitive portion in the $3^{\prime}$-noncoding region of a Cb-specific mRNA transcribed from a single-copy gene (Heinlein et al., 1986). Of all $\mathrm{Cb}$-positive clones containing repetitive elements, only the two L1-related ones produce a distinct Northern blot signal specific for poly(A) ${ }^{+}$RNA from mature cerebellum. Northern blots hybridized with cloned non-LINE inter- 


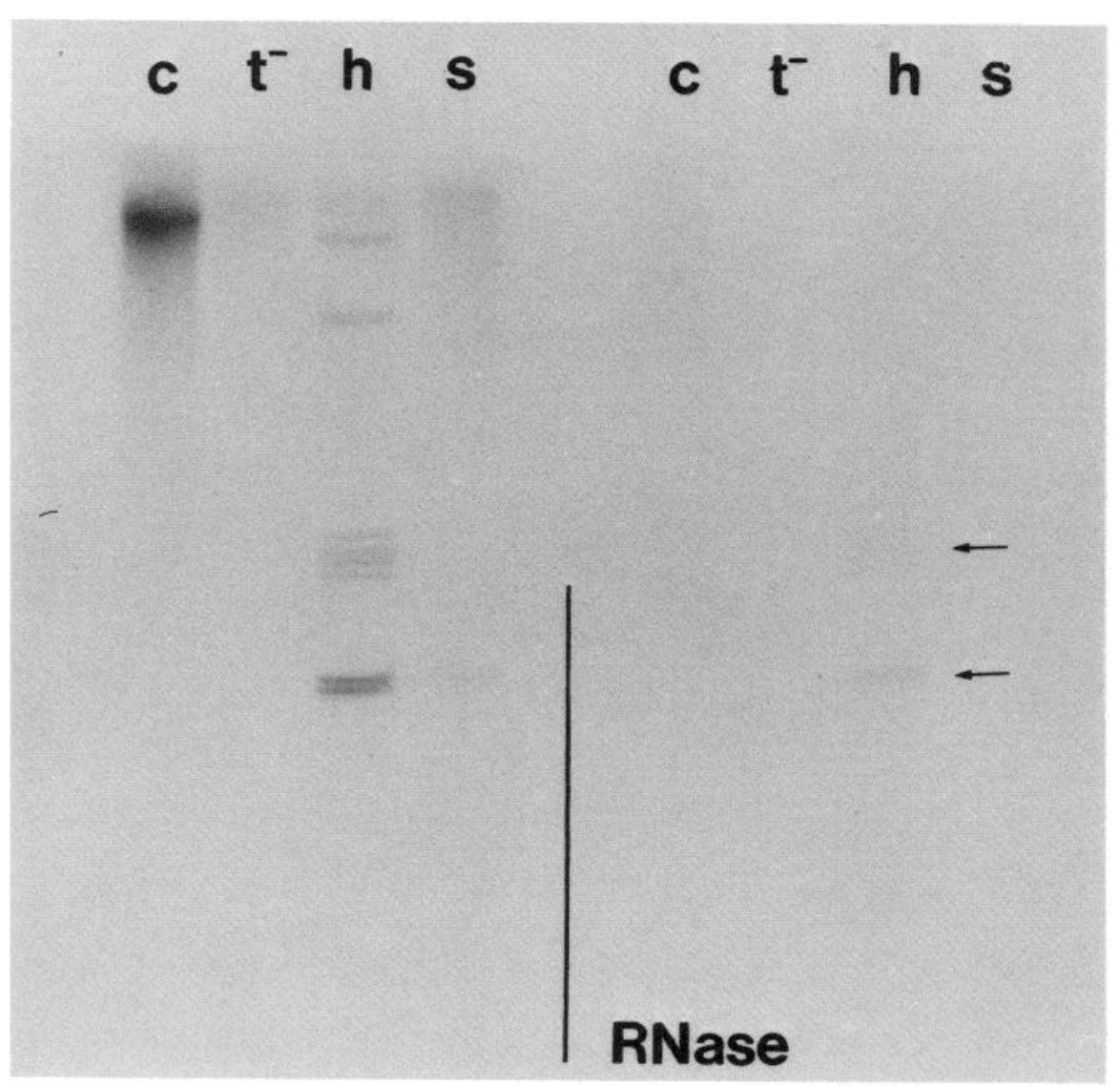

Figure 4. Northern blot analysis of total RNAs from adult mouse tissues either untreated (left) or exposed to RNase (right) prior to electrophoresis. Blots of citrate/urea gels (see legend to Fig. 3) were hybridized with a nicktranslated R-family subclone derived from CebA117 (see Fig. 1). Hybridization with E27 gave similar results (not shown). After treatment of RNAs with $10 \mu \mathrm{g}$ RNase for $40 \mathrm{~min}$ at $37^{\circ} \mathrm{C}$, only 2 series of bands (arrows) in lane $h$ were still faintly visible. Abbreviations as in Figure 3.

spersed repetitive mouse DNA (B1, B2, LLRep1, and 3) also fail to exhibit specific hybridization (not shown). These facts exclude false signals due to contamination of the poly(A) ${ }^{+}$RNA with randomly shared genomic DNA.

Artificial cloning of repetitive elements from contaminating genomic DNA is unlikely, although not impossible using the vector-primed cDNA cloning system according to Okayama and Berg (1983). The Cb-specific signal on Northern blots, on the other hand, is exclusively due to large RNA transcripts, as demonstrated by its RNase sensitivity (Fig. 4). "Run-on" analyses of cerebellar nuclei in the presence and absence of low concentrations of $\alpha$-amanitin (carried out according to Schibler et al., 1983; Powell et al., 1984) indicate (Schaal, 1986) that this large RNA-species is transcribed by RNA polymerase II. A transcription of LINEs by RNA polymerase II has already been described for human cells by Shafit-Zagardo et al. (1983) and Heller et al. (1984).

While the L1-related signal in Northern blots of total cerebellar RNA preparations represents RNA exclusively (Fig. 4, lane $c$ ), some of the L1-hybridizing material derived from heart

Figure 5. Northern blot analysis of nuclear RNAs with L1-sequence probes (RS5 and RS13). Lane 1, Adult cerebellar cytoplasmic poly(A)+RNA; lane 2, cerebellar nuclear RNA; lane 3, nuclear RNA of total brain; lane 4, marker (arrows indicate, top to bottom, $1.6 \mathrm{~kb}, 1.0$ $\mathrm{kb}, 631$ nucleotides, 517/506 nucleotides, 400 nucleotides, and 344 nucleotides). In lane 3 of the original X-ray film there is also a very weak signal at the position (indicated by the open arrow) that cannot be reproduced photographically.

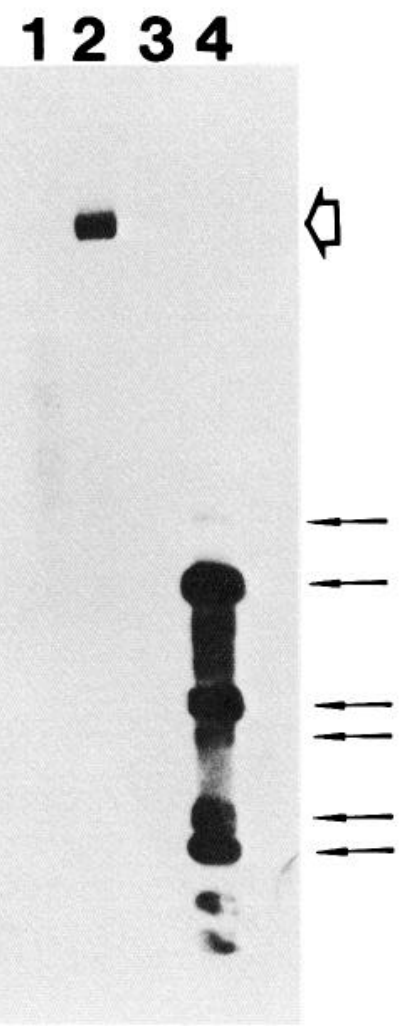


Figure 6. In situ hybridization of sagittal sections of adult mouse brain using CebA117 as a probe. Sections $(4 \mu \mathrm{m}$ thick) of the whole brain were hybridized with either biotinylated $(a-d, f)$ or ${ }^{3} \mathrm{H}$-labeled $(e) \mathrm{CebA} 117$ probes (for details see Materials and Methods). $a-d$, Same section; $c$ and $d$, higher-magnification photomicrographs (using Nomarski differential-interference contrast microscopy) of the areas indicated by the circles in $a$ and $b$, respectively. The dark reaction products are sites of hybridization. The open arrows in $b$ and $f$ indicate the fascia dentata of the hippocampal formation; the arrows in $c$ mark Purkinje cell somata. Section $e$ was counterstained with methyl green after autoradiography; section $f$ was treated with $2 \times \mathrm{SSC}$ for $10 \mathrm{~min}$ at $70^{\circ} \mathrm{C}$ prior to in situ hybridization, resulting in hybridization to all nuclei in brain. Final magnification: $\times 25(a, b, f)$ and $\times 630(c-e)$.
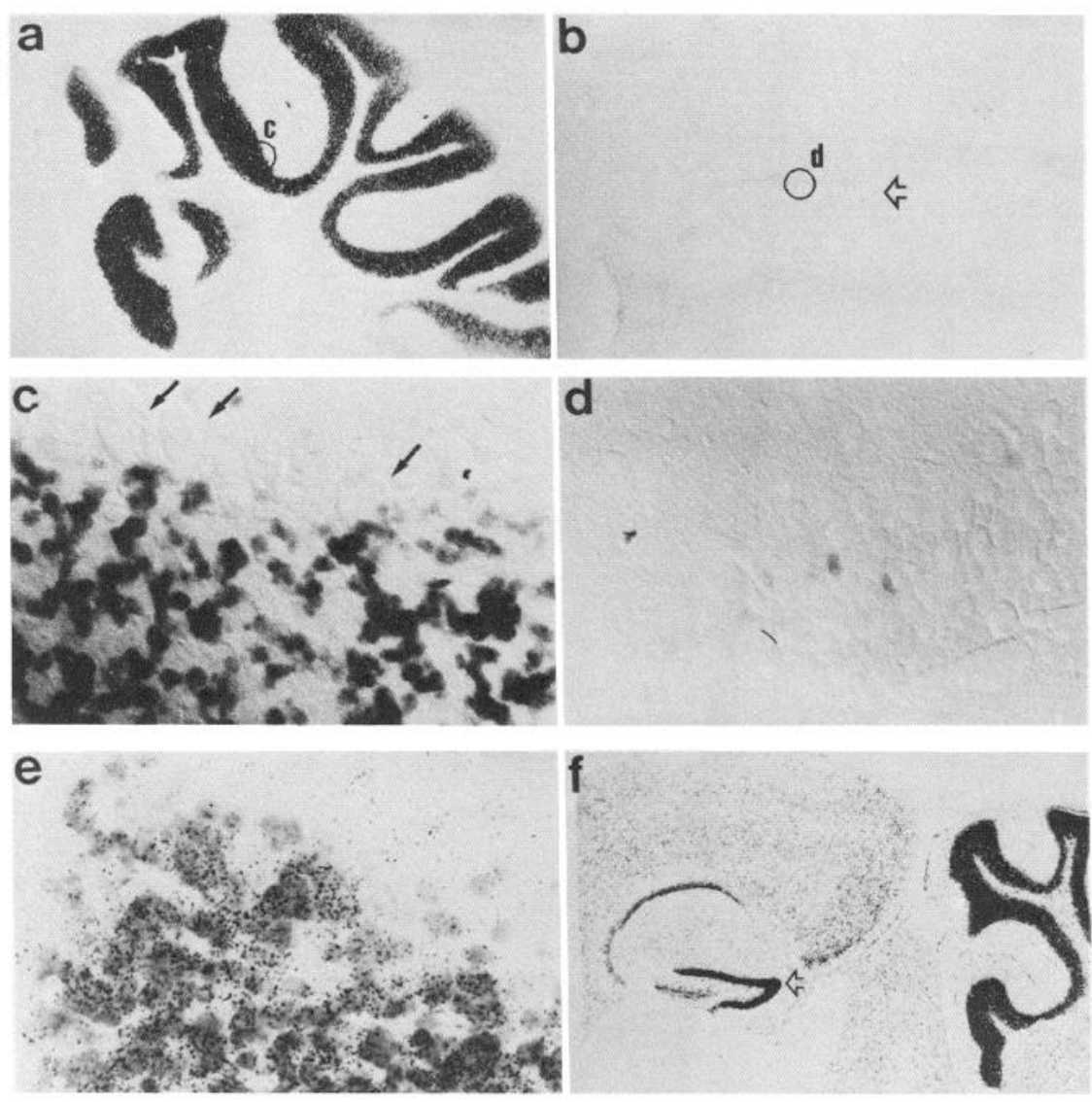

muscle seems to be RNase resistant. Since they disappear after additional DNase treatment, these bands possibly represent extrachromosomal DNA generated by reverse transcription of repetitive sequences, as suggested for the Alu-family (Krolewski and Rush, 1984) and a transposon-like element in human DNA (Paulson et al., 1985).

Transcription of LINEs has been observed in several tissues and cell lines (DiGiovanni et al., 1983; Kole et al., 1983; Lerman et al., 1983; Shafit-Zagardo et al., 1983; Soriano et al., 1983; Witney and Furano, 1984; Skowronski and Singer, 1985). Such RNA intermediates of LINE sequences and their reverse transcripts have been suggested as links in the evolutionary mechanism creating interspersed repetitive elements in chromosomal DNA of eukaryotes (Kole et al., 1983; Lerman et al., 1983; Sharp, 1983; Cooper et al., 1984; Baltimore, 1985; Singer and Skowronski, 1985; Soares et al., 1985; Deininger and Daniels, 1986).

Relatively little is known about tissue, cell, or developmental specificity of LINE transcription. Soriano et al. (1983) mention a higher proportion of BamHI transcripts $(=\mathrm{L} 1 \mathrm{Md})$ in mouse brain than in liver. Jackson et al. (1985), on the other hand, did not observe an altered quantitative expression of L1Md sequences in any tissue or cell line (liver, brain, kidney, and hepatoma cells). Their results may reflect the absence or presence of cerebellum in brain tissue preparations. A more specific expression of human LINE-1 has been observed in teratocarcinoma cells (NTera2 clone D1), especially when the cells display embryonal carcinoma morphology (Skowronski and Singer, 1985).
In situ hybridization of labeled probe confirmed the cerebellar-specific expression of CebA117 transcripts. Furthermore, the hybridization signal was localized very specifically to the granule cells. Thus, we conclude from Northern blot and in situ hybridization signals that CebA1 17 represents polyadenylated, L1related RNA transcripts highly accumulated in adult cerebellar granule cells. In agreement with RNA subfraction studies (see below), CebA117 transcripts were densely distributed throughout the granule cell perikaryon, which is predominantly occupied by the nucleus. This nuclear localization is not due to a cytoplasmic signal overlying the nucleus, since the near-complete labeling of granule cells, the thinness of sections $(4 \mu \mathrm{m})$, and the size of the granule cells $(5-8 \mu \mathrm{m})$ preclude such a possibility. Finally, because of the high copy number of L1 sequences in genomic murine DNA, all nuclei in brain are apparently recognized when in situ hybridization conditions favor DNA:DNA interaction.

The subfraction of total RNA, in which the LINE transcripts are enriched, differs from system to system. Soriano et al. (1983) found LINE sequences of mouse tissues in polyribosomal poly (A) ${ }^{+}$mRNA, while Shafit-Zagardo et al. (1983) identified the human LINE analog in transcripts enriched in nuclear poly(A)- RNA of HeLa cells. The cerebellum transcript of L1 Md is highly concentrated in the nuclear poly $(\mathrm{A})^{+} \mathrm{RNA}$ fraction, and significantly fewer copies appear in cytoplasmic poly(A)+RNA (Fig. 5).

With the exception of the $6.5 \mathrm{~kb}$ LINE-1 transcript in human teratocarcinoma cells (Skowronski and Singer, 1985), LINE sequences are commonly present in heterogeneous transcripts 
(Jackson et al., 1985; Soares et al., 1985). In contrast, the size distribution of the cerebellum-specific L1-RNA is rather homogeneous.

Theoretically, the L1-containing transcript can also be a cerebellum-specific unspliced hnRNA species that carries Ll-sequence motifs in intron portions. This possibility cannot be excluded unless the transcript has been sequenced in its entirety. However, the abundance of the transcript argues against this assumption. According to approximate quantifications of ethidium bromide-stained gels, exposure times of Northern blots (compared with transcripts of known abundance), and the intensity of the signals of the in situ hybridizations (Fig. 6), the abundance of the Ll-related transcript can be estimated to be $1-2 \%$ of total nuclear RNA (not shown).

For the following reasons we believe that the L1-related transcript in the mouse cerebellum is a tissue-specific characteristic:

1. The molecule that hybridizes with the L1Md probes is RNA synthesized by RNA polymerase II.

2. Accumulation of $\mathrm{Ll}$ transcripts is restricted to mature cerebellum (apparent approximately at postnatal day 7 as determined by Northern blot and at P21-30 as demonstrated by in silu hybridization analysis; data not shown).

3. The L1 transcript is specific for cerebellar granule cells.

4. The $\mathrm{L} 1$ transcript is homogeneous in size and abundant in mouse and rat cerebellum.

5. The cerebellum-specific signal on Northern blots is specific for L1 sequences (SINE probes do not recognize this RNA species).

6. Most of the L1-related transcript copies are polyadenylated, and only the sense strand in the normal $\mathrm{Ll}$ orientation is present in the cerebellum.

7. The use of animals from different facilities (Cologne and Philadelphia) diminishes the probability of an infectious virus encoding L1-related transcripts.

The question of whether the cerebellar L1 transcript serves a particular function remains unanswered. Although at least some of the LINE transcripts contain long open-reading frames (Martin et al., 1984; Singer and Skowronski, 1985; D'Ambrosio et al., 1986) and the L1 Md sequence in various species of the genus Mus is highly conserved (Jubier-Maurin et al., 1985) it seems unlikely that the transcript in the rodent cerebellum is translated, because it is accumulated mainly in nuclear poly $(\mathrm{A})^{+} \mathrm{RNA}$. A possible involvement in regulatory events according to a model postulated for repetitive sequences by Davidson and Britten (1979) can be neither affirmed nor denied. More specific regulation models for brain-specific gene expression by use of interspersed repetitive elements ("ID") (Sutcliffe and Milner, 1984), if they are valid at all (Owens et al., 1985; Herget et al., 1986; Sapienza and St-Jacques, 1986), seem to be even less likely.

We consider as a simple hypothesis that L1 transcripts are synthesized in all cells but are normally quickly removed by posttranscriptional degradation. This catabolic mechanism may be defective in cerebellar granule cells.

\section{References}

Aviv, H. and P. Leder (1972) Purification of biologically active globin messenger RNA by chromatography on oligothymidylic acid-cellulose. Proc. Natl. Acad. Sci. USA 69: 1408-1412.

Baltimore, D. (1985) Retroviruses and retrotransposons: The role of reverse transcription in shaping the eukaryotic genome. Cell 40:481482.

Bennett, K. L., and N. D. Hastie (1984) Looking for relationships between the most repeated dispersed DNA sequences in the mouse:
Small $\mathrm{R}$ elements are found associated consistently with long MIF repeats. EMBO J. 3: 467-472.

Biggin, M. D., T. J. Gibson, and G. F. Hong (1983) Buffer gradient gels and ${ }^{35}$ S-label as an aid to rapid DNA sequence determination. Proc. Natl. Acad. Sci. USA 80: 3963-3965.

Brown, S. D. M., and M. Piechaczyk (1983) Insertion sequences and tandem rcpetitions as sources of variation in a dispersed repeat family. J. Mol. Biol. 165: 249-256.

Cooper, R., C. E. Herzog, M.-L. Li, W. F. Zapisek, P. R. Hoyt, H, Ratrie, III, and J. Papaconstantinou (1984) Localization of the L1Md family of repeated sequences in the mouse albumin- $\alpha$-fetoprotein gene complex. Nucleic Acids Res. 12: 6575-6586.

D'Ambrosio, E., S. D. Waitzkin, F. R. Witney, A. Salemme, and A. V. Furano (1986) Structure of highly repeated, long interspersed DNA family (LINE or LIRn) of the rat. Mol. Cell. Biol. 6: 411-424.

Davidson, E. H., and R. J. Britten (1979) Regulation of gene expression: Possible role of repetitive sequences. Science 204: 1052-1059.

Deininger, P. L., and G. R. Daniels (1986) The recent evolution of mammalian repetitive DNA elements. Trends Genet. 2: 76-80.

Denhardt, D. T. (1966) A membrane filter technique for the detection of complementary DNA. Biochem. Biophys. Res. Commun. 23:641646.

Devereux, J., P. Haeberli, and O. Smithies (1984) A comprehensive set of sequence analysis programs for the VAX. Nucleic Acids Res. 12. 387-395.

DiGiovanni, L., S. R. Haynes, R. Misra, and W. R. Jelinek (1983) Kpn I family of long dispersed repeated DNA sequences of man: Evidence for entry into genomic DNA of DNA copies of poly(A)terminated Kpn I RNAs. Proc. Natl. Acad. Sci. USA 80: 6533-6537.

Efstratiadis, A., and F. C. Kafatos (1976) The chorion of insects: Techniques and perspectives. Methods Mol. Biol. 8: 1-124.

Fanning, T. G. (1982) Characterization of a highly repetitive family of DNA sequences in the mouse. Nucleic Acids Res. 10: 5003-5013.

Fanning, T. G. (1983) Size and structure of the highly repetitive BAM $\mathrm{HI}$ element in mice. Nucleic $A$ cids Res. 11: 5073.5091.

Gebhard, W., and H. G. Zachau (1983) Organization of the R family and other interspersed repetitive DNA sequences in the mouse genome. J. Mol. Biol. 170: 255-270.

Hanahan, D. (1983) Studies on transformation of $E$. coli with plasmids. J. Mol. Biol. 166: 557-580.

Heinlein, U. A. O., R. Lange-Sablitzky, H. Schaal, and W. Wille (1986) Molecular characterization of the MT-family of dispersed middlerepetitive sequences in rodent genomes. Nucleic Acids Res. 14:64036416.

Heller, D., M. Jackson, and L. Leinwand (1984) Organization and expression of non-Alu family interspersed repetitive DNA sequences in the mouse genome. J. Mol. Biol. 173: 419-436.

Herget, T., M. Reich, K. Stüber, and A. Starzinski-Powitz (1986) Regulated expression of repetitive sequences including the identifier sequence during myotube formation in culture. EMBO J. 5: 659-664.

Holmes, D. S., and M. Quigley (1981) A rapid boiling method for the isolation of bacterial plasmids. Anal. Biochem. 114: 193-198.

Jackson, M., D. Heller, and L. Leinwand (1985) Transcriptional measurements of mouse repeated DNA sequences. Nucleic Acids Res. 13: 3389-3403.

Jubier-Maurin, V., B. J. Dod, M. Bellis, M. Piechaczyk, and G. Roizes (1985) Comparative study of the L1 family in the genus Mus. Possible role of retroposition and conversion events in its concerted evolution. J. Mol. Biol. 184: 547-564.

Kaplan, B. B., S. I. Rernstein, and A. F. Gioio (1979) An improved method for the rapid isolation of brain ribonucleic acid. Biochem. J. 183: 181-184.

Kole, L. B., S. R. Haynes, and W. R. Jelinek (1983) Discrete and heterogeneous high molecular weight RNAs complementary to a long dispersed repeat family (a possible transposon) of human DNA. J. Mol. Biol. 165: 257-286.

Krayev, A. S., D. A. Kramerov, K. G. Skryabin, A. P. Ryskov, A. A Bayev, and G. P. Georgiev (1980) The nucleotide sequence of the ubiquitous repetitive DNA sequence $B 1$ complementary to the most abundant class of mouse fold-back RNA. Nucleic Acids Res. 8: 12011215.

Krayev, A. S., T. V. Markusheva, D. A. Kramerov, A. P. Ryskov, K. G. Skryabin, A. A. Bayev, and G. P. Georgiev (1982) Ubiquitous transposon-like repeats $B 1$ and $B 2$ of the mouse genome: $B 2$ sequencing. Nucleic Acids Res. 10: 7461-7475. 
Krolewski, J. J., and M. G. Rush (1984) Some extrachromosomal circular DNAs containing the Alu family of dispersed repetitive sequences may be reverse transcripts. J. Mol. Biol. 174: 31-40.

Lehrach, H., D. Diamond, J. M. Wozney, and H. Boedtker (1977) RNA molecular weight determinations by gel electrophoresis under denaturing conditions, a critical reexamination. Biochemistry 16:47434751.

Lerman, M. I., R. E. Thayer, and M. F. Singer (1983) Kpn I family of long interspersed repeated DNA sequences in primates: Polymorphism of family members and evidence for transcription. Proc. Natl. Acad. Sci. USA 80: 6966-6970.

Lizardi, P. M., R. Binder, and S. A. Short (1984) Preparative isolation of DNA and biologically active mRNA from diethylaminoethyl membrane. Gene Anal. Tech. 1: 33-39.

Loomis, W. F., and M. E. Gilpin (1986) Multigene families and vestigial sequences. Proc. Natl. Acad. Sci. USA 83: 2143-2147.

Martin, S. L., C. F. Voliva, F. H. Burton, M. H. Edgell, and C. A. Hutchison, III (1984) A large interspersed repeat found in mouse DNA contains a long open reading frame that evolves as if it encodes a protein. Proc. Natl. Acad. Sci. USA 81: 2308-2312.

Mason, A. J., B. A. Evans, D. R. Cox, J. Shine, and R. I. Richards (1983) Structure of mouse kallikrein gene family suggests a role in specific processing of biologically active peptides. Nature $303: 300$ 307.

Melton, D. A., P. A. Krieg, M. R. Rebagliati, T. Maniatis, K. Zinn, and M. R. Green (1984) Efficient in vitro synthesis of biologically active RNA and RNA hybridization probes from plasmids containing a bacteriophage SP6 promotor. Nucleic Acids. Res. 12: 7035-7056.

Messing, J., and J. Vieira (1982) A new pair of M13 vectors for selecting either DNA strand of double-digest restriction fragments. Gene 19: 269-276.

Molloy, P. L., and R. H. Symons (1980) Cleavage of DNA-RNA hybrids by type II restriction enzymes. Nucleic Acids Res. 8: 29392946.

Okayama, H., and P. Berg (1983) A cDNA cloning vector that permits expression of cDNA inserts in mammalian cells. Mol. Cell. Biol. 3: 280-289.

Owens, G. P., N. Chaudhari, and W. E. Hahn (1985) Brain "Identifier" Sequence" is not restricted to brain: Similar abundance in nuclear RNA of other organs. Scicnce 229: 1263-1265.

Paulson, K. E., N. Deka, C. W. Schmid, R. Misra, C. W. Schindler, M. G. Rush, L. Kadyk, and L. Leinwand (1985) A transposon-like element in human DNA. Nature 316: 359-361.

Pelham, H. R. B., and R. J. Jackson (1976) An efficient mRNAdependent translation system from reticulocyte lysates. Eur. J. Biochem. 67: 247-256.

Potter, S. S. (1984) Rearranged sequences of a human Kpn I element. Proc. Natl. Acad. Sci. USA 81: 1012-1016.

Powell, D. J., J. M. Friedman, A. J. Ouellette, K. S. Krauter, and J. E. Darnell, Jr. (1984) Transcriptional and post-transcriptional control of specific messenger RNAs in adult and embryonic liver. J. Mol. Biol. 179: 21-35.

Rigby, P. W. J., M. Dieckmann, C. Rhodes, and P. Berg (1977) Labcling dcoxyribonuclcic acid to high specific activity in vitro by nick translation with DNA polymerase I. J. Mol. Biol. 113: 237-251.
Rogers, J. H. (1985) The origin and evolution of retroposons. Int. Rev. Cytol. 93: 187-279.

Sanger, F., S. Nicklen, and A. R. Coulson (1977) DNA-sequencing with chain-terminating inhibitors. Proc. Natl. Acad. Sci. USA 74 : 5463-5467.

Sapienza, C., and B. St-Jacques (1986) "Brain-specific" transcription and evolution of the identifier sequence. Nature 319:418-420.

Schaal, H. (1986) Isolierung und Charakterisierung spezifischer cDNAKlone aus dem Kleinhirn der Maus. Ph.D. thesis, University of Köln, F.R.G.

Schibler, U., O. Hagenbüchle, P. K. Wellauer, and A. C. Pittet (1983) Two promoters of different strength control the transcription of the mouse alpha-amylase gene Amy-1 in the parotid gland and the liver. Cell 33: 501-508.

Shafit-Zagardo, B., F. L. Brown, P. J. Zavodny, and J. J. Maio (1983) Transcription of the KpnI families of long interspersed DNAs in human cells. Nature 304: 277-280.

Sharp, P. A. (1983) Conversion of RNA to DNA in mammals: Alulike elements and pseudogenes. Nature 301: 471-472.

Singer, M. F. (1982) SINEs and LINEs: Highly repeated short and long interspersed sequences in mammalian genomes. Cell 28: 433434.

Singer, M. F., and J. Skowronski (1985) Making sense out of LINEs: Long interspersed repeat sequences in mammalian genomes. Trends Biochem. Sci. 10: 119-122.

Singer, M. F., R. E. Thayer, G. Grimaldi, M. I. Lerman, and T. G. Fanning (1983) Homology between the KpnI primate and BamHI (MIF-1) rodent families of long interspersed repeated sequences. $\mathrm{Nu}-$ cleic Acids Res. 11: 5739-5745.

Skowronski, J., and M. F. Singer (1985) Expression of a cytoplasmic LINE-1 transcript is regulated in a human teratocarcinoma cell line. Proc. Natl. Acad. Sci. USA 82: 6050-6054.

Soares, M. B., E. Schon, and A. Efstratiadis (1985) Rat LINE1: The origin and evolution of a family of long interspersed middle repetitive DNA elements. J. Mol. Evol. 22: 117-133.

Soriano, P., M. Meunier-Rotival, and G. Bernardi (1983) The distribution of interspersed repeats is nonuniform and conserved in the mouse and human genomes. Proc. Natl. Acad. Sci. USA 80: 18161820.

Southern, E. (1975) Detection of specific sequences among DN $\Lambda$ fragments separated by gel electrophoresis. J. Mol. Biol. 98: 503-507.

Sutcliffe, J. G., and R. J. Milner (1984) Brain specific gene expression. Trends Biochem. Sci. 9: 95-99.

Taub, F., and E. B. Thompson (1982) An improved method for preparing large arrays of bacterial colonies containing plasmids for hybridization: In situ purification and stable binding of DNA on paper filters. Anal. Biochem. 126: 222-230.

Voliva, C. F., S. L. Martin, C. A. Hutchison, III, and M. H. Edgell (1984) Dispersal process associated with the L1 family of interspersed repetitive DNA sequences. J. Mol. Biol. 178: 795-813.

Wilbur, W. J., and D. J. Lipman (1983) Rapid similarity searches of nucleic acid and protein data banks. Proc. Natl. Acad. Sci. USA 80: 726-730.

Witney, F. R., and A. V. Furano (1984) Highly repeated DNA families in the rat. J. Biol. Chem. 259: 10481-10492. 